\title{
Phase Tunable Calcium Phosphate Biomaterials Synthesis and Application in Protein Delivery
}

Chi Ching Lau, Philip James Thomas Reardon ${ }^{\ddagger}$, Jonathan Campbell Knowles ${ }^{\mathrm{Il}}$ and Junwang $\operatorname{Tang}^{*, \neq}$

${ }^{\ddagger}$ Department of Chemical Engineering, University College London, Torrington Place, London WC1E 7JE, UK

"Division of Biomaterials and Tissue Engineering, University College London Eastman Dental Institute, 256 Gray's Inn Road, London, WC1X 8LD, UK

${ }^{\S}$ Department of Nanobiomedical Science \& BK21 Plus NBM Global Research Center for Regenerative Medicine, Dankook University, Cheonan 330-714, Republic of Korea

KEYWORDS: protein loading and release, calcium phosphates, phase control, morphology, microwave

\section{ABSTRACT}

Calcium phosphates $(\mathrm{CaP})$ are important biomaterials used in tissue engineering and drug delivery, due to their biocompatibility, low toxicity, and osteoconductivity. However, controlling the phase of $\mathrm{CaP}$, especially tricalcium phosphate (TCP), is very challenging under mild conditions, particularly when using one preparation protocol for all $\mathrm{CaP}$ phases. It is also crucial to produce these biomaterials economically and reproducibly. Herein, three of the most commonly employed $\mathrm{CaP}$, including beta-tricalcium phosphate $(\beta$-TCP), dicalcium phosphate anhydrous (DCPA), and hydroxyapatite (HA) were, for the first time, successfully synthesised by altering the reaction solvent, using calcium acetate monohydrate as a precursor and a rapid microwave-assisted synthetic method. A variety of $\mathrm{CaP}$ particle morphologies were obtained, including elliptical and plate-shaped with different porosities. Compared with conventional 
heating, CaP biomaterials synthesised using microwave heating showed greater reproducibility, higher yields, and shorter reaction time. By varying the reaction solvents, morphologies and phases of $\mathrm{CaP}$ were controlled, leading to an enhanced protein bovine serum albumin (BSA) loading, with a higher BSA absorption observed according to the trend DCPA $>\beta$-TCP $>$ HA. Furthermore, the phase, specific surface area and pores size were shown to play decisive roles in protein desorption with a higher release amount observed according to the trend DCPA $>\beta$-TCP $>$ HA. Finally it is found that larger pores are also beneficial to BSA adsorption.

\section{INTRODUCTION}

Calcium phosphates $(\mathrm{CaP})$ are a group of inorganic compounds present in mammalian bone and teeth. They have gained increasing interest in bone regeneration and drug delivery, owing to their low toxicity, excellent biocompatibility, nonimmunogenicity and osteoconductive properties. ${ }^{1,2,3,5} \mathrm{CaP}$ materials are used in a wide range of biomedical products such as coatings on orthopaedic and dental implants, prosthetic coatings and composites, as well as scaffolds for bone regrowth, depending on their resorbability and bioactivity. ${ }^{6,7}$ For instance, the least soluble $\mathrm{CaP}$ phase, hydroxyapatite (HA), is widely applied as a coating in orthopaedic and dental implants, and in liquid chromatography of biological compounds due to chemical similarities to the minerals in bone and teeth. On the other hand, other $\mathrm{CaP}$ phases such as beta-tricalcium phosphate ( $\beta$-TCP) and dicalcium phosphate anhydrous (DCPA), which exhibits a higher aqueous solubility and hence resorption rate compared with HA, can also act as a degradable

drug carrier and scaffold material. ${ }^{2,8}$ Finally, the most important advantage of CaP biomaterials is that their degradation in the human body does not create any toxic substances compared to some polymers (e.g. polycaprolactone). ${ }^{9}$ 
Formation of $\mathrm{CaP}$ phases relies on the presence of components from orthophosphoric acid $\left(\mathrm{H}_{3} \mathrm{PO}_{4}\right)$, i.e. $\mathrm{H}_{2} \mathrm{PO}_{4}{ }^{-}, \mathrm{HPO}_{3}{ }^{2-}$, or $\mathrm{PO}_{4}{ }^{3-}$ ions. ${ }^{10} \beta-\mathrm{TCP}\left[\mathrm{Ca}_{3}\left(\mathrm{PO}_{4}\right)_{2}\right]$, DCPA $\left[\mathrm{CaHPO}_{4}\right]$ and $\mathrm{HA}\left[\mathrm{Ca}_{10}\left(\mathrm{PO}_{4}\right)_{6}(\mathrm{OH})_{2}\right]$, possessing $\mathrm{Ca} / \mathrm{P}$ ratios ranging from 1 to 1.67 , are amongst the most useful calcium phosphate phases in the biomedical field. Acidity and solubility of these $\mathrm{CaP}$ materials are inversely related to the $\mathrm{Ca} / \mathrm{P}$ ratio. Hence, the relative solubility of these phases is as follows; DCPA > $\beta$-TCP > HA. ${ }^{11,12}$

$\mathrm{CaP}$ compounds can be categorized into (i) low-temperature $\mathrm{CaP}$ and (ii) hightemperature $\mathrm{CaP}$, where the former can be formed in an aqueous solution at low temperature and is a potential precursor for the high-temperature phases (e.g. $\beta$-TCP and HA). ${ }^{12}$ On the other hand, synthesis of $\beta$-TCP typically requires reaction temperatures above $700-800{ }^{\circ} \mathrm{C} .{ }^{5}$ Generally, it is a two-step reaction, firstly either the calcium deficient hydroxyapatite (CDHA) or an intermediate phase (amorphous calcium phosphate) is obtained before transforming into $\beta$-TCP when increasing in the reaction time. ${ }^{13,14}$ Several low-temperature methods have been studied to synthesise the high-temperature $\mathrm{CaP}$ phases, including both $\beta$-TCP and HA, but at the cost of exponentially increasing the reaction time (e.g. more than 8 hours to crystallise $\beta$-TCP particles) and subsequent control of particle shape is generally poor. ${ }^{14}$ Hence, the synthesis of different $\mathrm{CaP}$ phases with a high yields under mild reaction conditions still remains a challenge.

By using microwave-assisted synthesis, various $\mathrm{CaP}$ phases can be targeted using an identical preparation pathway as developed in this study. Microwave heating is based on dielectric heating where the heat is generated internally due to the rotation, friction and collisions 
of molecules as the permanent dipole moment of solvent molecules attempts to align with the applied electromagnetic field. It can allow the low temperature and fast production of crystalline particles with controlled morphology, high yields and heating rates, better selectivity and improved reproducibility. ${ }^{15,16,17,18}$ The heating rate and efficiency of microwave heating depends on the nature of the coupling of the reaction mixture with the microwave field $(\tan \delta)$. Therefore in this study, strong microwave absorbing solvents, (i.e. methanol, ethanol and water) were used to allow fast and homogeneous heating during the reaction. Various $\mathrm{CaP}$, from low temperature to high temperature phases (e.g. $\beta$-TCP, DCPA and HA), were successfully fabricated without any additional surfactants. As a result, no additional steps were required to remove the surfactants, simplifying the synthesis process and lowering the cost. Interestingly, calcium acetate monohydrate was found to be a suitable precursor for the synthesis of different phases of calcium phosphates under identical mild experimental conditions, which could not be achieved by other precursors (for example, calcium nitrate tetrahydrate and calcium hydroxide). ${ }^{19}$

$\mathrm{CaP}$ materials are widely used as drug carriers and non-viral gene carriers. Systematic delivery of drugs in the human body suffers from problems associated with enzymatic degradation and adverse effects when traveling in human blood. ${ }^{20}$ Conversely, localised delivery of therapeutics using $\mathrm{CaP}$ nanovectors can offer reduced toxicity and improved efficacy. For instance, a combination of $\mathrm{CaP}$ bioceramics and proteins, e.g. bone morphogenetic proteins or fibronectin, can notably improve the osteogenic potential of bone substitutes and reduce the recovery period by enhancing the osteoblastic differentiation. ${ }^{21}$ Nano-sized CaP particles are highly interesting drug delivery agents, as their higher specific surface areas provide increased carrier sites. Furthermore, nanocarriers can significantly overcome the limitations of direct 
delivery by reducing the possibility of enzymatic degradation and possible hazardous side effects. $^{20}$ In addition, nano-sized $\mathrm{CaP}$ particles more closely mimic the natural bone nanostructure and induce bone regrowth more effectively. ${ }^{22}$ Hence, increasing efforts have been made to control the particle size, porosity, shape, surface structure and internal structure of $\mathrm{CaP}$ nanomaterials to improve drug carrier properties. However, control over the loading capacity and release properties still remain an important challenge in the biomedical area. ${ }^{2}$ The efficacy of these carriers for drug delivery is strongly dependent on the ability to bind the drug effectively, which is dominated by electrostatic forces between the drug molecules and the material surface. ${ }^{7}$ In addition, controlling material morphology and porosity can provide the desired surface area for optimum adsorption of drug molecules. ${ }^{23}$ Thus, by tuning the phase and morphology of $\mathrm{CaP}$, control of protein loading and release rate should be possible. Therefore this study focuses on the control of phase, morphology and porosity of $\mathrm{CaP}$ by a facile route, in an attempt to manipulate the drug adsorption and release properties of these highly biocompatible materials.

\section{EXPERIMENTAL SECTION}

Synthesis: Preparation of CaP nanomaterials was prepared using modified literature procedures. ${ }^{2}$ For $\beta$-TCP preparation, $0.79 \mathrm{~g}$ of $\mathrm{Ca}\left(\mathrm{C}_{2} \mathrm{H}_{3} \mathrm{O}_{2}\right)_{2} \cdot \mathrm{H}_{2} \mathrm{O}$ (Sigma) and $0.33 \mathrm{~g}$ of $\mathrm{H}_{3} \mathrm{PO}_{4}($ Acros Organics) were each dissolved in $20 \mathrm{~mL}$ methanol, at room temperature. $\mathrm{The}_{3} \mathrm{HO}_{4}$ solution was added drop-wise to the Ca solution, then transferred into a sealed PTFE container equipped with a stirrer bar, before inserting into the microwave (MARS, CEM). The hydrothermal/solvothermal reaction was pre-set to 25 minutes of ramping time and 5 minutes of holding at $200{ }^{0} \mathrm{C}$. The output power of microwave was adjusted automatically to maintain the temperature and ramp rate. Finally, the suspended product was separated and purified by centrifugation and washed 
several times with ethanol before drying at $70{ }^{\circ} \mathrm{C}$ for $12 \mathrm{~h}$. The procedure was repeated by replacing methanol with ethanol and water for preparation of DCPA and HA, respectively.

Characterisation: Phase identification by PXRD was carried out using a Bruker D8 Advance Powder X-ray Diffractometer with a $\mathrm{CuK} \alpha(\lambda=0.154060 \mathrm{~nm})$ radiation source. Diffraction patterns were collected from $10^{\circ}$ to $80^{\circ}$ with a step size of $0.02^{\circ}$ and 10 seconds of step time. These patterns were compared with the standard spectra from the JCPDS database. Raman spectra data were acquired using a Renishaw Raman Microscope with helium-neon laser at a wavelength of $514.5 \mathrm{~nm}$. Morphologies of samples were observed using a 2x JEOL 1010 Transmission Electron Microscope (TEM) and JEOL 7401 high resolution Field Emission Scanning Electron Microscope (SEM) which was operated at $2 \mathrm{kV}$. In order to improve the SEM image quality, the powder samples were pretreated by Au coating.

Protein/BSA loading and release: Bovine serum albumin (BSA) was used to study in vitro protein loading and releasing profile. The loading and release experiments were conducted as previously reported. ${ }^{2}$ Briefly: $0.25 \mathrm{~g}$ of $\mathrm{CaP}$ sample was added to $50 \mathrm{ml}$ of BSA solution $(1 \mathrm{mg} / \mathrm{mL})$ and then stirred for 24 hours at room temperature. The BSA loading amount was calculated based on the depletion of BSA in the solution measured by UV-Vis spectroscopy (Shimadzu UV2550 in the $277-280 \mathrm{~nm}$ range). $0.25 \mathrm{~g}$ of loaded sample was then incubated in 10 $\mathrm{mL}$ of phosphate buffer solution at room temperature. $2 \mathrm{~mL}$ aliquots of solution were removed and then replaced with fresh buffer solution at pre-set time intervals. The BSA concentration at different time points was measured by UV-vis. A baseline with water or phosphate buffer was 
performed before each measurement. A calibration plot $(0.1-1 \mathrm{mg} / \mathrm{mL})$ using known BSA concentrations was undertaken to calculate the concentrations of the loading and release samples.

\section{RESULTS AND DISCUSSION}

\section{Analysis of Calcium Phosphates}

A rapid and homogeneous microwave heating method was chosen in this study to enhance the selectivity of $\mathrm{CaP}$ phases and control particle morphology. This unique chemical method produced high yields of three important $\mathrm{CaP}$ phases, including $\beta$-TCP, DCPA and HA, by altering the solvent and using calcium acetate monohydrate as a precursor (calcium nitrate tetrahydrate and calcium hydroxide did not yield $\beta$-TCP under similar experimental condition, XRD pattern not shown herein). The chemical reactions occurring in this study are based on the acid-base reaction, (i.e. acidic phosphoric acid with basic calcium acetate), but $\beta$-TCP is the

neutral phase, whilst DCPA and HA are slightly acidic and basic, respectively. ${ }^{24}$ Initially, CaP biomaterials were synthesised via microwave irradiation at $200{ }^{\circ} \mathrm{C}$, using a 5 minute reaction time. As depicted in Figure 1, a different $\mathrm{CaP}$ phases were obtained using different solvents while keeping the same precursor $\mathrm{Ca} / \mathrm{P}$ molar ratio constant and without adjustment in $\mathrm{pH}$. All XRD patterns were matched with JCPDS database; $\beta$-TCP (JCPDS \#09-0169), DCPA (JCPDS \#9-80), HA (JCPDS \#09-0432) or brushite (JCPDS \#09-0077). 


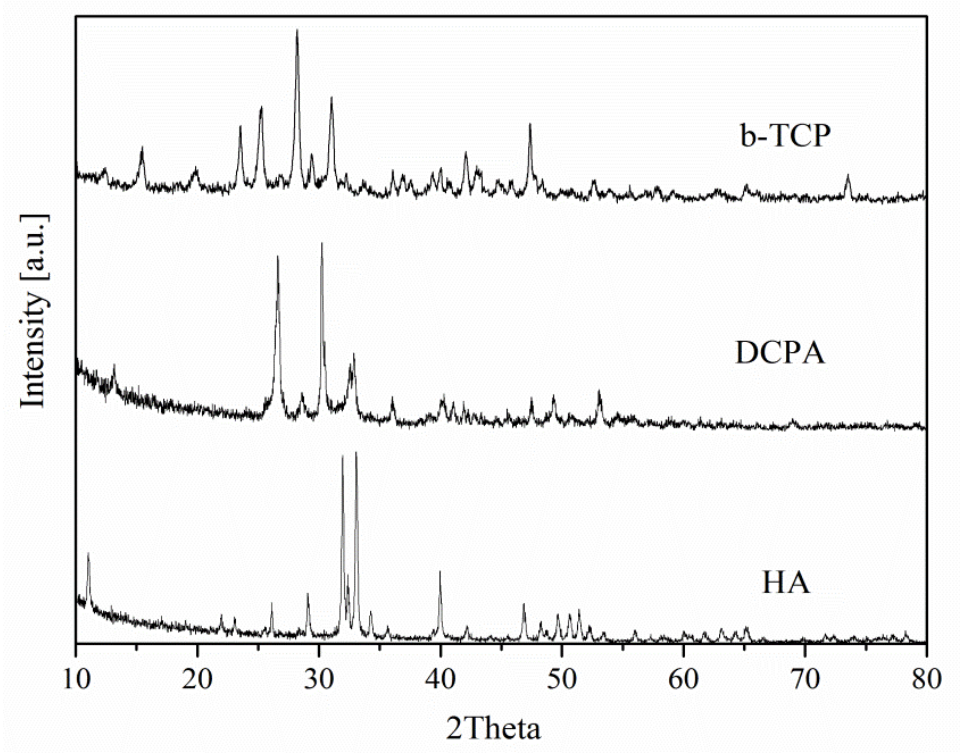

Figure 1. $\mathrm{XRD}$ patterns of $\mathrm{CaP}$ phases ( $\beta$-TCP in methanol, DCPA in ethanol and $\mathrm{HA}$ in water) prepared at $200{ }^{\circ} \mathrm{C}$ for 5 minutes via the microwave method.

The synthesised CaP particles appear to have a preferred growth orientation according to the solvent used, resulting in a variation in morphology, observed by TEM (Figure 2). After a reaction time of five minutes, DCPA particles were found to be elliptical with a dimension of 50$110 \mathrm{~nm} \times 40-90 \mathrm{~nm}$, HA materials were plate-like in shape $(1-5 \mu \mathrm{m} \times 0.4-1.2 \mu \mathrm{m})$, while $\beta$-TCP were needle-shaped nanoparticles with a $20-80 \mathrm{~nm} \times 10-20 \mathrm{~nm}$. Short reaction times resulted in low yields, for example, less than $10 \% \beta$-TCP was produced when the reaction time was 5 minutes. However, when the microwave reaction time further increased to one hour, no change in calcium phosphate phase was found (as verified through XRD, see Supporting Information, S1), but the longer reaction time increased the yield and also changed the morphology (Figure 3 and Supporting Information, S2). A narrow particle size distribution of $\beta$-TCP nanoparticles was observed for the sample synthesised for 30 minutes (Supporting Information, S3), however the yield was still low at $24 \%$. After one hour, $\beta$-TCP nanoparticles grew from needle-shaped to 
elliptical with dimensions $50-120 \mathrm{~nm} \times 40-80 \mathrm{~nm}$ and a porous surface (Figure 3). DCPA particles transformed from elliptical into larger flat plate-like particles with dimensions of 140$950 \mathrm{~nm} \times 100-240 \mathrm{~nm}$. The shape of HA particles did not change but they increased in dimensions to $2-10 \mu \mathrm{m} \times 0.4-2 \mu \mathrm{m}$. When the reaction time was further increased to two hours, the yield of the CaP nanoparticles was similar to that achieved after one hour reaction time, implying that the reactions achieved equilibrium after $1 \mathrm{~h}$. Therefore, it can be concluded that the optimum synthesis conditions are a temperature of $200{ }^{\circ} \mathrm{C}$ with one hour of residence time in the microwave, resulting in a high yield of $\mathrm{CaP}$ materials, (e.g. $80.72 \%$ for $\beta$-TCP. $85.11 \%$ for DCPA and $91.99 \%$ for HA).
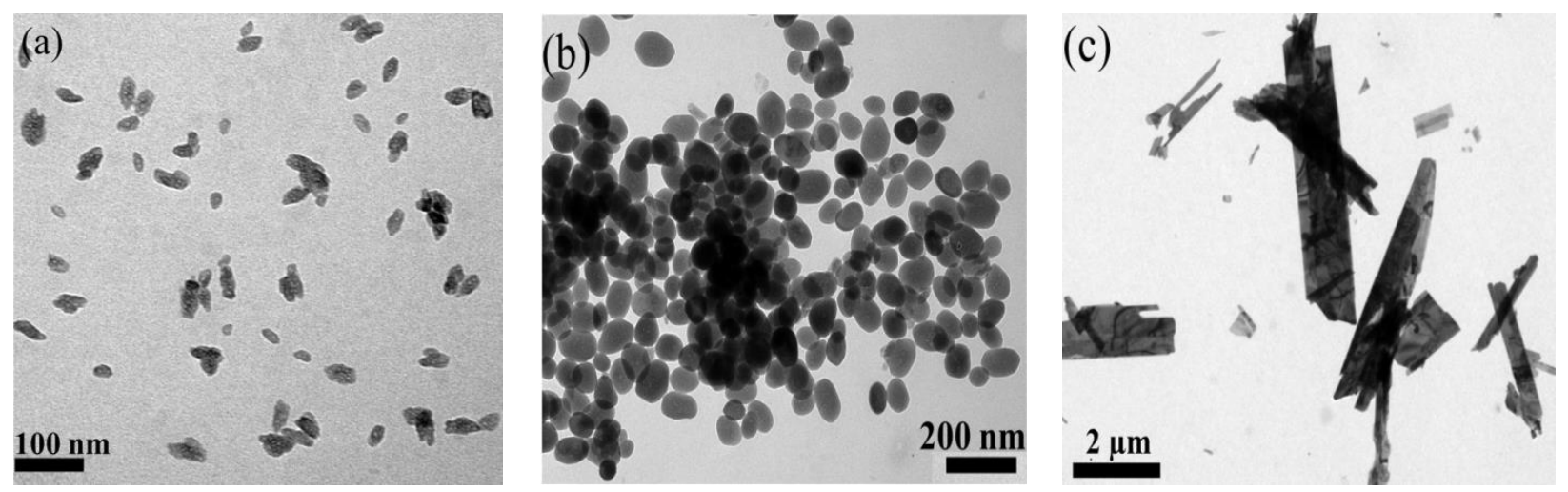

Figure 2. TEM images of (a) needle-like $\beta$-TCP nanoparticles, (b) elliptical DCPA particles and (c) plate-like HA particles synthesised after 5 minutes microwave heating at $200{ }^{\circ} \mathrm{C}$. 

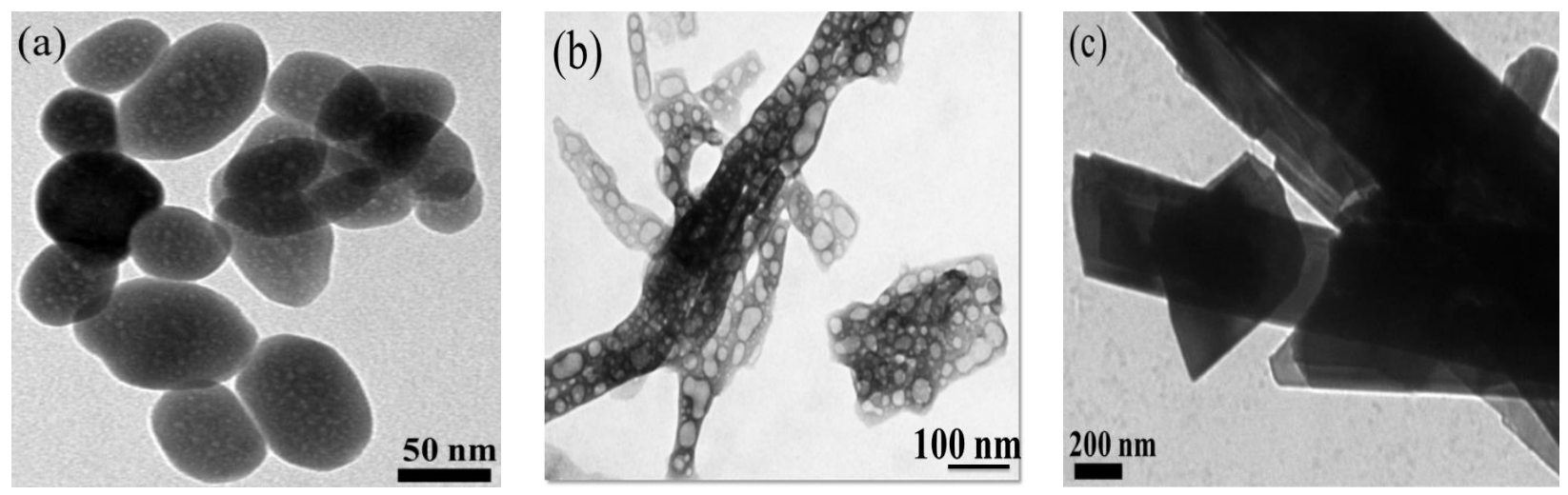

Figure 3. TEM images for (a) $\beta$-TCP nanoparticles, (b) DCPA and (c) HA particles produced using microwave heating at $200{ }^{0} \mathrm{C}$ for one hour.

The high yield of all three phases of $\mathrm{CaP}$ indicates that the temperature was high enough to provide sufficient energy not only to drive the reaction, but also to drive it to completion. The Raman Spectra of $\beta$-TCP, DCPA and HA samples are similar to the literature (Supporting information, S4). ${ }^{25,26,27,28}$ Raman peaks at 291, 404, 470, 548, 611, 631, 734, 948, 967 and 1005 $\mathrm{cm}^{-1}$ correspond to those found in $\beta$-TCP, while characteristic Raman peaks of DCPA were seen at $392,419,562,576,591,901,987$ and $1097 \mathrm{~cm}^{-1} .{ }^{25,27,28} \mathrm{HA}$ only has four main Raman peaks, which are found at 430, 592, 962 and $1046 \mathrm{~cm}^{-1} .^{25,26}$

Table 1. Specific surface area, product yield and weight percentage of BSA loaded onto different CaP surfaces ( $\beta$-TCP, DCPA and HA) obtained at $200{ }^{\circ} \mathrm{C}$ and one hour reaction time.

\begin{tabular}{|l|c|c|c|c|}
\hline Type of & Phase & Yield (\%) & BET Specific & BSA Loading \\
solvent & & & Surface Area $\left(\mathrm{m}^{2} / \mathrm{g}\right)$ & $(\mathrm{wt} . \%)$ \\
\hline Methanol & $\beta-\mathrm{TCP}$ & 80.72 & 34.4 & 41 \\
\hline
\end{tabular}




\begin{tabular}{|l|c|c|c|c|}
\hline Ethanol & DCPA & 85.11 & 77.8 & 50 \\
\hline Water & HA & 91.99 & 16.1 & 15 \\
& & & & \\
\hline
\end{tabular}

The mesoporosity of $\beta$-TCP, DCPA and HA particles (prepared at $200{ }^{\circ} \mathrm{C}$ with one hour holding time) was further analysed by nitrogen adsorption/desorption analysis. DCPA shows a type IV isotherm indicative of a mesoporous material, with a relatively narrow distribution of pore diameters as shown by the sharp peak in the range of 4-12 $\mathrm{nm}$ in the BJH plot (Figure 4). $\beta$ TCP nanoparticles exhibit a similar type IV isotherm but a larger pore size of 10-40 nm. Only HA particles obtained in this study show a type II isotherm with zero pore volume, indicating that they are nonporous. Regarding the specific surface area, DCPA particles have the largest specific surface area $\left(77.8 \mathrm{~m}^{2} / \mathrm{g}\right)$, followed by TCP $\left(34.4 \mathrm{~m}^{2} / \mathrm{g}\right)$ and then HA particles $\left(16.1 \mathrm{~m}^{2} / \mathrm{g}\right)$ (see Table 1), consistent with their pore volume.

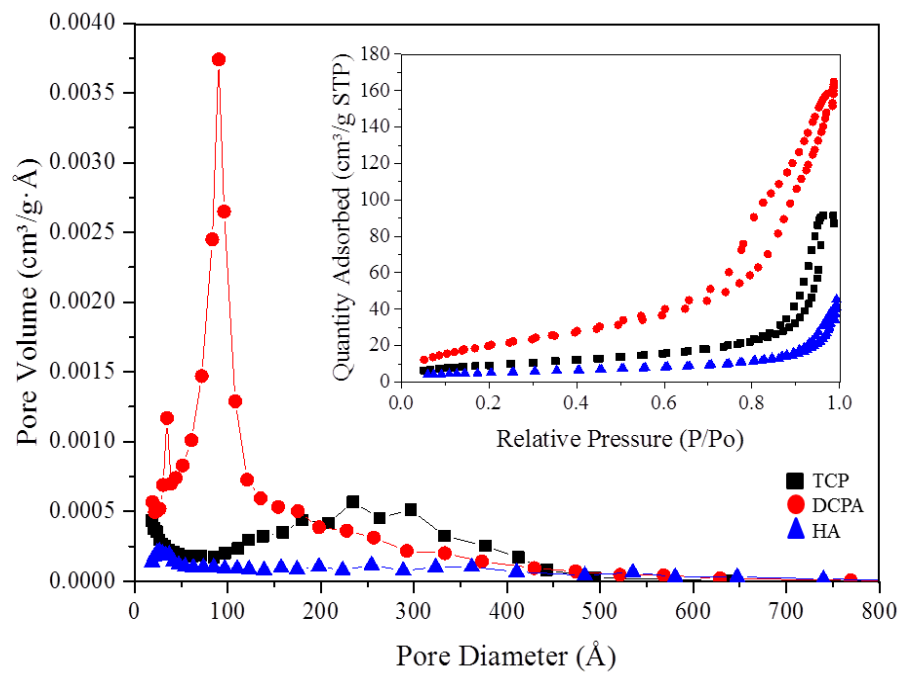

Figure 4. Pore size distribution and $\mathrm{N}_{2}$ adsorption-desorption equilibrium isotherm of $\beta$-TCP, DCPA and HA particles formed at $200{ }^{\circ} \mathrm{C}$ and one hour residence time in microwave. 


\section{Phase Selection of Calcium Phosphates}

Chemical reactions in microwave synthesis are highly dependent on the nature of reaction solvent. No reaction occurred in both alcohol solvents (methanol and ethanol) before microwave irradiation due to the low solubility of calcium precursors in alcohols, while brushite directly formed after mixing both precursors in water (Supporting information, S5). Reactions in methanol (Equation 1a and 1b), ethanol (Equation 2) and water (Equation 3a and 3b) are shown below:

$$
\begin{aligned}
& \mathrm{Ca}\left(\mathrm{CH}_{3} \mathrm{COO}\right)_{2}+\mathrm{H}_{3} \mathrm{PO}_{4} \rightarrow \mathrm{ACP}+2 \mathrm{CH}_{3} \mathrm{COOH} \\
& \mathrm{ACP} \rightarrow \mathrm{Ca}_{3}\left(\mathrm{PO}_{4}\right)_{2} \\
& \mathrm{Ca}\left(\mathrm{CH}_{3} \mathrm{COO}\right)_{2}+\mathrm{H}_{3} \mathrm{PO}_{4} \rightarrow \mathrm{CaHPO}_{4}+2 \mathrm{CH}_{3} \mathrm{COOH} \\
& \mathrm{Ca}\left(\mathrm{CH}_{3} \mathrm{COO}\right)_{2}+2 \mathrm{H}_{2} \mathrm{O}+\mathrm{H}_{3} \mathrm{PO}_{4} \rightarrow \mathrm{CaHPO}_{4} \cdot 2 \mathrm{H}_{2} \mathrm{O}+2 \mathrm{CH}_{3} \mathrm{COOH} \\
& \mathrm{CaHPO}_{4} \cdot 2 \mathrm{H}_{2} \mathrm{O} \rightarrow \mathrm{Ca}_{10}\left(\mathrm{PO}_{4}\right)_{6}(\mathrm{OH})_{2}
\end{aligned}
$$

$\beta$-TCP and HA follow a two-step reaction sequence. Bow et al. reported that amorphous calcium phosphate (ACP) is initially obtained through mixing these two precursors at room temperature using methanol as a solvent. ${ }^{14}$ After undergoing microwave dielectric heating, the non-crystalline ACP is transformed into a crystalline $\mathrm{CaP}(\beta-\mathrm{TCP})$ in methanol with acetic acid as the by-product (Equation 1a and 1b). In water, brushite immediately precipitated (Equation 3a) after addition of the phosphoric acid into the calcium precursor solution and acted as the

precursor to HA (Equation 3b). ${ }^{7}$ Indeed, water is always needed in the chemical transformation of brushite, therefore, it is hydraulic compared to other phases. ${ }^{24}$ For DCPA, no initial phase was formed when mixing the two precursors at room temperature (as found by XRD-not reported 
herein) as calcium acetate is totally insoluble in ethanol at room temperature. However, after microwave assisted heating, slow dissolution and calcium ion release allowed the formation of DCPA (Equation 2).

Microwave heating in a closed vessel system produces a high vapour pressure that can further facilitate $\mathrm{CaP}$ nucleation and growth. For example, methanol is a highly volatile organic solvent. Hence, it produced the highest vapour pressure, 400-550 psi, followed by ethanol with approximately $300-400 \mathrm{psi}$ and water at $110-200 \mathrm{psi}$ (measured by a pressure probe located in the cavity of the microwave reaction system -see Supporting Information, S6). However, the vapour pressure of the solvents does not play a decisive role in the final product phase formed but may contribute in combination with microwave heating to accelerate the reaction rate, as $\beta$ TCP, DCPA and HA can be synthesised at room temperature in similar solvents but with an extended reaction time. ${ }^{14,29,30}$ For instance, synthesis of both $\beta$-TCP and DCPA require five minutes microwave irradiation instead of approximately eight and three hours, respectively at room temperature. ${ }^{14,30}$ Furthermore, reducing the reaction temperature of microwave assisted synthesis to ca. $70{ }^{\circ} \mathrm{C}$ did not produce any $\beta$-TCP in five minutes. Therefore, the rapid synthesis and phase selectivity of $\mathrm{CaP}$ biomaterials is the product of both a highly pressurized system and rapid heating associated with our microwave assisted synthesis.

Table 2. Dissipation factors $(\tan \delta), \mathrm{pK}_{\mathrm{a}}$ of phosphoric acids in solvents and polarity data for methanol, ethanol and water. ${ }^{31,32,33}$

\begin{tabular}{|l|c|c|c|}
\hline Solvents & $\mathrm{pK}_{\mathrm{a}}$ & Polarity index & $\tan \delta\left(\times 10^{-4}\right)$ \\
\hline Methanol & 5.15 & 5.1 & 6400 \\
\hline
\end{tabular}




\begin{tabular}{|l|c|c|c|}
\hline Ethanol & 6.15 & 5.2 & 2500 \\
\hline Water & 2.11 & 9.0 & 1570 \\
& & & \\
\hline
\end{tabular}

By excluding the aforementioned factors, solubility of precursors in different solvents (Table 2) plays a critical role in controlling the phase of calcium phosphates and morphology. The nucleation rate of $\mathrm{CaP}$ is determined by the concentration of calcium and phosphate ions in solution. ${ }^{24}$ This concentration is dependent on the solubility of precursors (calcium acetate monohydrate and phosphoric acid) in the different reaction solvents. The calcium and phosphate ions, from calcium acetate monohydrate and phosphoric acid, interact chemically and precipitate as the end product or form the intermediates for additional $\mathrm{CaP}$ phases. For instance, brushite which precipitated before microwave heating acts as an intermediate precursor for HA in water. Water is a highly polar solvent, so the degree of dissociation of both precursors is relatively higher. For example, calcium acetate monohydrate dissolves in water, but only partially dissolves in alcohols at room temperature. ${ }^{34}$ Consequently, the higher solubility of precursors in water leads to the insoluble HA phase produced in water. Furthermore, the $\mathrm{pK}_{\mathrm{a}}$ value in water $\left(\mathrm{pK}_{\mathrm{a}}=2.11\right)$ indicates a higher dissociation of phosphoric acid than in alcohol $\left(\mathrm{pK}_{\mathrm{a}}=5.15-6.15\right)$, which shifts the reaction from left to right (Equation 4) and more $\mathrm{HPO}_{4}^{2-}$ ions favour brushite and then HA formation in water. ${ }^{35}$

$\mathrm{H}_{3} \mathrm{PO}_{4} \rightleftharpoons \mathrm{H}_{2} \mathrm{PO}_{4}^{-} \rightleftharpoons \mathrm{HPO}_{4}^{2-} \rightleftharpoons \mathrm{PO}_{4}^{3-}$

In addition, $\mathrm{Ca} / \mathrm{P}$ ratio of these phases and the solubility of precursors are intimately related. Indeed, the use of alcohols tends to reduce the $\mathrm{Ca} / \mathrm{P}$ ratio of the final $\mathrm{CaP}$ phase. ${ }^{36}$ Based on 
Table 1, HA, with the highest $\mathrm{Ca} / \mathrm{P}$ ratio, was prepared in water because the degree of dissociation of both precursors in water are relatively higher than both in alcohols, and $\mathrm{OH}^{-}$ions were present in water. Calcium acetate monohydrate is slightly soluble in methanol and almost insoluble in ethanol, hence, the $\mathrm{Ca}^{2+}$ ion concentration in ethanol at room temperature would be lower than in methanol. Amorphous calcium phosphate, with $\mathrm{Ca} / \mathrm{P}$ molar ratio of $1.2-2.2$, was obtained when mixing the two precursors in methanol after a few hours at room temperature. ${ }^{14,37}$ Therefore, $\beta$-TCP preferably forms in methanol due to slightly higher concentration of calcium ions than in ethanol in which DCPA with a low $\mathrm{Ca} / \mathrm{P}$ ratio of 1.00 was produced.

\section{Morphology Control of Calcium Phosphates}

The morphology of $\mathrm{CaP}$ produced was strongly influenced by the type of reaction solvent. Solute-solvent interaction can change the crystal growth kinetics and surface energy, thus enhancing or inhibiting growth at certain crystal faces. ${ }^{38,39}$ Reardon et al. reported that the morphology evolution of $\mathrm{CaP}$ materials relied on the concentration of the residue precursors in the solution after the formation of nuclei; a higher precursor concentration favours onedimensional growth and a lower precursor concentration allowed three-dimensional growth of nanocrystals. ${ }^{17} \mathrm{~A}$ measure of the efficiency of a solvent to convert the absorbed microwave energy to thermal energy is known as the dissipation factor tan $\delta$, as listed in Table 2; higher tan $\delta$ values indicates greater heat dissipation to the solvent molecules, allowing a more rapid achievement of the desired temperature. ${ }^{33}$ Therefore, a faster heating and higher vapour pressure produce an environment in which nucleation is faster, in the order methanol $>$ ethanol $>$ water. Larger amounts of nuclei which form decreases the precursor ion concentration or the chemical 
potential in alcoholic solvents, thus favouring three-dimensional growth of crystals and leading to small needle-shaped $\beta$-TCP and elliptical DCPA particles in methanol and ethanol, respectively. Inversely, a high precursor ion concentration in water resulted on a preference for one-dimensional growth. ${ }^{17}$ Furthermore, the reaction time also affected the size and morphology of the crystals; larger crystals were obtained with longer reaction times. As the reaction time was extended, the needle-shaped $\beta$-TCP particles transformed into regular elliptical shapes in methanol, DCPA agglomerated into larger plate shapes in ethanol (some smaller particles still can be seen in Supporting Information, S2). HA retained its morphology but increased in size.

\section{Protein Loading and Release}

The loading efficiency of therapeutic agents and general bioactivity were studied using bovine serum albumin (BSA) as a model protein. BSA loading was carried out for 24 hours to ascertain the drug delivery performance of the $\mathrm{CaP}$ biomaterials. The specific surface area and pore size of $\mathrm{CaP}$ materials influenced the protein adsorption capacity. Table 1 displays the amount of BSA adsorbed onto the three $\mathrm{CaP}$ materials. DCPA particles have the largest specific surface area $\left(77.8 \mathrm{~m}^{2} / \mathrm{g}\right)$, followed by $\beta$-TCP $\left(34.4 \mathrm{~m}^{2} / \mathrm{g}\right)$ and then HA particles $\left(16.1 \mathrm{~m}^{2} / \mathrm{g}\right)$ as shown in Table 1, consistent with their pore volume. The micron plate-shaped HA particles prepared in water as a solvent showed a $15 \mathrm{wt} \%$ BSA loading due to its comparatively small surface area of $16.1 \mathrm{~m}^{2} / \mathrm{g}$. A threefold increase in loading efficiency for DCPA particles compared to HA particles was found, which correlates with the $380 \%$ increase in surface area and higher meso-porosity observed. $\beta$-TCP particles represent a $41 \mathrm{wt} \%$ loading of BSA, only 18 wt\% less than DCPA although its surface area is 2 times smaller than DCPA. 
The adsorption of $\mathrm{BSA}$ molecules onto $\mathrm{CaP}$ particle surfaces is mainly driven by the electrostatic interaction between the charged amino acids in the BSA molecule and the CaP particle surface where the highly ionic $\mathrm{CaP}$ surface exerts greater electrostatic forces to interact with the functional groups in BSA molecules. ${ }^{20,40,41}$ Specifically, this interaction occurs between $\mathrm{Ca}^{2+}$ in the $\mathrm{CaP}$ and $\mathrm{COO}^{-}$in $\mathrm{BSA}$ molecules. A higher surface area increases the overall charge per unit weight (more $\mathrm{Ca}^{2+}$ ions on the surfaces) which results in a higher degree of electrostatic interaction between $\mathrm{CaP}$ and $\mathrm{BSA}^{20}$ Therefore, the smallest surface area HA with fewest $\mathrm{Ca}^{2+}$ adsorption sites on the surface adsorbed the least amount of BSA molecules. Zhu et al. reported that greater amounts of protein adsorbed onto porous surfaces, concluding that the higher porosity produced more binding sites, ${ }^{21}$ and is in agreement with our results- highly porous DCPA adsorbs the highest amount of BSA. It was also reported that the pore size also affects the BSA adsorption capacity; large mesopores allow more large biomolecules such as BSA (ellipsoid with dimensions $14 \mathrm{~nm}$ x $3.8 \mathrm{~nm}$ x $3.8 \mathrm{~nm}$ ) to be adsorbed. ${ }^{23,42,43}$ The $\beta$-TCP material has less than half the surface area of the DCPA sample, but demonstrated ca. $82 \%$ of the BSA loading amount achieved by DCPA. This strongly indicates that the mesoporous structure of $\beta$ TCP (15-40 nm) can host more BSA molecules in comparison to the smaller pores (4-12 $\mathrm{nm})$ in DCPA. Conversely, HA has the smallest surface area and a nonporous structure, resulting in the smallest loading amount of BSA. This characteristic suggests that drug loading may be controlled by not only surface area but also pore size. 


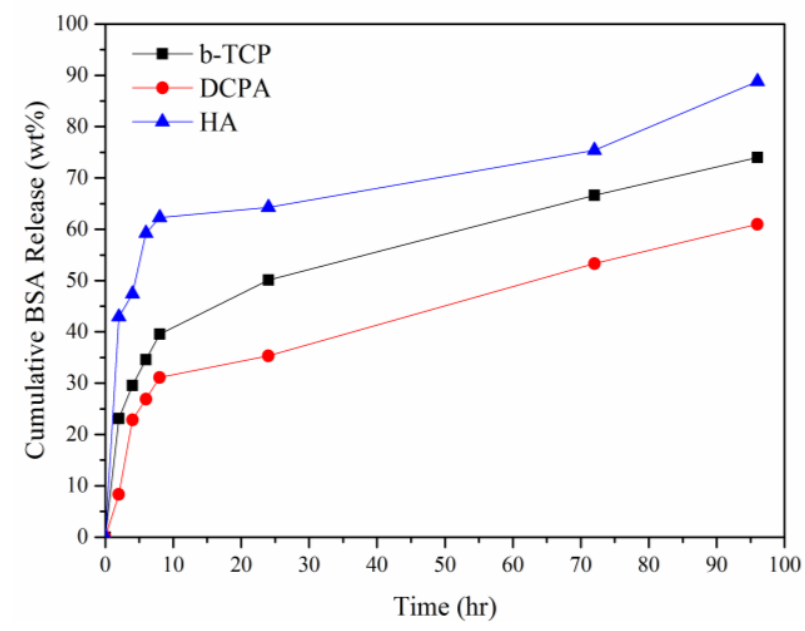

(a)

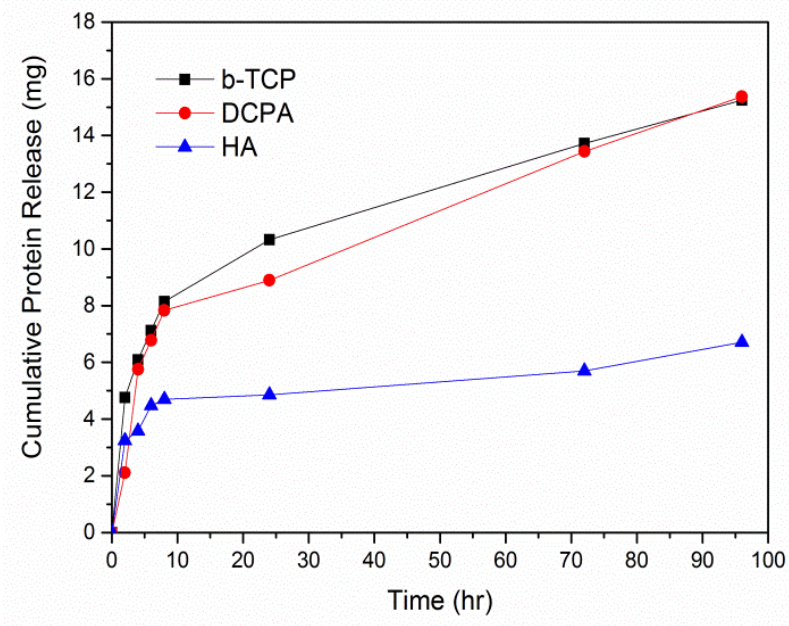

(b)

Figure 5. Protein release profile for: (a) Cumulative BSA release (wt $\%$ ) using different CaP ( $\beta$ TCP, DCPA and HA) based on loading efficiency. (b) Cumulative amount of protein release (mg) from $\beta$-TCP, DCPA and HA surfaces over 96 hours. All the CaP samples were synthesised at $200{ }^{\circ} \mathrm{C}$, with one hour of microwave heating.

The other important aspect of a drug delivery medium is its release profile. The BSAloaded $\mathrm{CaP}$ samples were incubated in vitro to examine this property. All the materials exhibit a two-stage release profile (Figure 5 (a) and (b)) consisting of an initial fast release stage (0-10 h), followed by a slow linear release stage (10-96 h). Based on Figure 5(a), the BSA released (wt\%) over the whole delivery period was the largest for HA, in comparison, DCPA exhibited the smallest release (wt\%), regardless of loading amount. It was found that $62 \mathrm{wt} \%$ of BSA (4.7 mg) was released from HA, $40 \mathrm{wt} \%(8.2 \mathrm{mg})$ from $\beta$-TCP and only $31 \mathrm{wt} \%(7.8 \mathrm{mg})$ of BSA from DCPA particles after the first 10 hours (Figure 5(b)). According to Figure 5 (a) and (b), the BSA released (in wt $\%$ and $\mathrm{mg}$ ) on three samples at the second stage are much slower compared with the first stage. It is estimated $100 \%$ of the protein would be released after 7 and 9 days from the $\beta$-TCP and DCPA particles respectively; in contrast to just 6 days for HA, which could be 
due to its lower adsorption capacity. During the second release phase (10-96 h), DCPA shows the largest release amount of BSA $(15.4 \mathrm{mg})$, compared to $15.2 \mathrm{mg}$ for $\beta$-TCP and only $6.7 \mathrm{mg}$ for HA. The total amount of BSA released from DCPA is expected to surpass $\beta$-TCP after 96 hours (Figure 5(b)).

The two-stage release mechanism for all $\mathrm{CaP}$ phases is determined by the physical states

of the adsorbed molecules and dissolution rate of $\mathrm{CaP}$ material. ${ }^{20,21,44}$ The fast initial release is attributed to loosely bonded BSA molecules (physical adsorbed molecules) present on the outer adsorption layers where the electrostatic forces are weak and dominated by surface area. The increase in the thickness of $\mathrm{BSA}$ layers on the $\mathrm{CaP}$ surfaces results in the molecules not being tightly bound. The second release stage is dominated by the dissolution rate of $\mathrm{CaP}$; higher solubility of $\mathrm{CaP}$ has a higher dissolution rate, enabling a higher amount of the BSA to be released (Figure 5(b)). ${ }^{20}$ Thus, the protein release amount is directly linked to CaP solubility: DCPA $>\beta$-TCP $>$ HA. However, another important influence of protein release rate is the pore size in which the BSA molecules are captured. Gao et al. reported that the drug molecules easily leaked out or released from the larger pore surfaces. ${ }^{43}$ Therefore, the larger pores of $\beta$-TCP can also explain the higher release amount of BSA compared to DCPA over the same release period. Therefore, it can be concluded that the release profile is affected by a trifecta of surface area, CaP dissolution rate and pore size.

\section{CONCLUSIONS}

In summary, morphology controlled CaP materials ( $\beta$-TCP, DCPA and HA) have been successfully synthesized in high yield (>80\%) using rapid microwave-assisted synthesis under 
mild processing conditions and short reaction times without addition of any surfactants. Furthermore, calcium acetate monohydrate was found to be the only suitable precursor to prepare different phases of $\mathrm{CaP}$. The $\mathrm{CaP}$ phases formed were shown to be controlled by the type of solvents used rather than the $\mathrm{Ca} / \mathrm{P}$ molar ratio, as well as residence time and reaction temperature/vapor pressure of solvents. This was attributed to the solubility of the precursors and polarity index of solvents. The efficacy of $\mathrm{CaP}$ biomaterials as drug carriers is strongly linked to their specific surface area and pore size. Increasing the specific surface area provides more binding sites; DCPA particles represented the highest loading amount of BSA (50 wt $\%$ ) in our study. The elliptical $\beta$-TCP nanoparticles exhibited a 41 wt $\%$ BSA loading, a 2.7 times enhancement in BSA loading capacity compared with the lowest surface area plate-shaped HA materials.

Interestingly, mesopores were formed in $\beta$-TCP and DCPA during preparation in alcohol solvents (methanol and ethanol) and resulted in higher BSA loading, demonstrating that the pore size also affects the loading capacity, with the larger pore size (similar to the size of BSA) of $\beta$ TCP increasing the adsorption of BSA macromolecules (cage effect).

Furthermore, the release of BSA from different $\mathrm{CaP}$ were characterised by a two-stage profile and were controlled by the surface area, dissolution rate of $\mathrm{CaP}$ and pore size. A higher dissolution rate of $\mathrm{CaP}$ facilitated a larger BSA release amount. Importantly, the larger pores in the $\beta$-TCP material may also influence the higher release amount of BSA compared to DCPA (smaller pore size) over the same release period. In short, the phase and morphology-controlled 
$\mathrm{CaP}$ materials provide a platform to readily control both the drug delivery profile and loading capacity of proteins.

\section{ASSOCIATED CONTENT}

Supporting Information. Additional materials characterisation (including XRD, SEM, Raman Spectra of CaP samples and vapour pressure profile of solvents) are included in the Supporting Information. This material is available free of charge via the Internet at http://pubs.acs.org.

\section{AUTHOR INFORMATION}

\section{Corresponding Author}

*E-mail: junwang.tang@ucl.ac.uk

\section{Notes}

The authors declare no competing financial interest.

\section{ACKNOWLEDGMENT}

CC Lau acknowledges the financial support of the Public Service Department Malaysia. Dr Mustafa Bayazit and Dr Savio Moniz are acknowledged for carrying out Raman Spectroscopy.

\section{REFERENCES}

(1) Uskoković, V.; Desai, T. A. Phase Composition Control of Calcium Phosphate Nanoparticles for Tunable Drug Delivery Kinetics and Treatment of Osteomyelitis. II. Antibacterial and Osteoblastic Response. J. Biomed. Mater. Res. A 2013, 101, 1427-1436. 
(2) Reardon, P. J. T.; Huang, J.; Tang, J. Morphology Controlled Porous Calcium Phosphate Nanoplates and Nanorods with Enhanced Protein Loading and Release Functionality. Adv. Healthc. Mater. 2013, 2, 682-686.

(3) Dorozhkin, S. V; Epple, M. Biological and Medical Significance of Calcium Phosphates. Angew. Chem. Int. Ed. Engl. 2002, 41, 3130-3146.

(4) Epple, M.; Ganesan, K.; Heumann, R.; Klesing, J.; Kovtun, A.; Neumann, S.; Sokolova, V. Application of Calcium Phosphate Nanoparticles in Biomedicine. J. Mater. Chem. 2010, 20, 18-23.

(5) Bohner, M.; Tadier, S.; Garderen, N. Van. Synthesis of Spherical Calcium Phosphate Particles for Dental and Orthopedic Applications. Biomatter 2013, 3, 1-15.

(6) Pattanayak, D. K.; Rao, B. T.; Mohan, T. R. R. Calcium Phosphate Bioceramics and Bioceramic Composites. J. Sol-Gel Sci. Technol. 2010, 59, 432-447.

(7) Kumta, P. N.; Sfeir, C.; Lee, D.H.; Olton, D.; Choi, D. Nanostructured Calcium Phosphates for Biomedical Applications: Novel Synthesis and Characterization. Acta Biomater. 2005, 1, 65-83.

(8) Ginebra, M. P.; Traykova, T.; Planell, J. A. Calcium Phosphate Cements as Bone Drug Delivery Systems: A Review. J. Control. Release 2006, 113, 102-110.

(9) Uskoković, V.; Uskoković, D. P. Nanosized Hydroxyapatite and Other Calcium Phosphates: Chemistry of Formation and Application as Drug and Gene Delivery Agents. J. Biomed. Mater. Res. B. Appl. Biomater. 2011, 96, 152-191.

(10) Barrère, F.; Blitterswijk, C. A. Van; Groot, K. de. Bone Regeneration: Molecular and Cellular Interactions with Calcium Phosphate Ceramics. Int. J. Nanomedicine 2006, 1, 317-332.

(11) Verron, E.; Khairoun, I.; Guicheux, J.; Bouler, J.-M. Calcium Phosphate Biomaterials as Bone Drug Delivery Systems: A Review. Drug Discov. Today 2010, 15, 547-552.

(12) Bohner, M. Calcium Orthophosphates in Medicine: From Ceramics to Calcium Phosphate Cements. Injury 2000, 31, 37-47.

(13) Kalita, S. J.; Bhardwaj, A.; Bhatt, H. A. Nanocrystalline Calcium Phosphate Ceramics in Biomedical Engineering. Mater. Sci. Eng. C 2007, 27, 441-449.

(14) Bow, J.-S.; Liou, S.-C.; Chen, S.-Y. Structural Characterization of Room-Temperature Synthesized Nano-Sized Beta-Tricalcium Phosphate. Biomaterials 2004, 25, 3155-3161.

(15) Bilecka, I.; Niederberger, M. Microwave Chemistry for Inorganic Nanomaterials Synthesis. Nanoscale 2010, 2, 1358-1374. 
(16) Rao, K. J.; Vaidhyanathan, B.; Ganguli, M.; Ramakrishnan, P. A. Synthesis of Inorganic Solids Using Microwaves. Chem. Mater. 1999, 11, 882-895.

(17) Reardon, P. J. T.; Handoko, A. D.; Li, L.; Huang, J.; Tang, J. Dimensionally and Compositionally Controlled Growth of Calcium Phosphate Nanowires for Bone Tissue Regeneration. J. Mater. Chem. B 2013, 1, 6170-6176.

(18) Moniz, S. J. A.; Tang, J. Charge Transfer and Photocatalytic Activity in CuO/TiO 2 Nanoparticle Heterojunctions Synthesised through a Rapid, One-Pot, Microwave Solvothermal Route. ChemCatChem 2015, 7,1659-1667.

(19) Shavandi, A.; A. Bekhit, A. E.-D.; Ali, A.; Sun, Z.; Ratnayake, J. T. Microwave-Assisted Synthesis of High Purity B-Tricalcium Phosphate Crystalline Powder from the Waste of Green Mussel Shells (Perna Canaliculus). Powder Technol. 2015, 273, 33-39.

(20) Dasgupta, S.; Bandyopadhyay, A.; Bose, S. Reverse Micelle-Mediated Synthesis of Calcium Phosphate Nanocarriers for Controlled Release of Bovine Serum Albumin. Acta Biomater. 2009, 5, 3112-3121.

(21) Zhu, X. D.; Zhang, H. J.; Fan, H. S.; Li, W.; Zhang, X. D. Effect of Phase Composition and Microstructure of Calcium Phosphate Ceramic Particles on Protein Adsorption. Acta Biomater. 2010, 6, 1536-1541.

(22) Sahoo, S. K.; Parveen, S.; Panda, J. J. The Present and Future of Nanotechnology in Human Health Care. Nanomedicine 2007, 3, 20-31.

(23) Sun, Z.; Deng, Y.; Wei, J.; Gu, D.; Tu, B.; Zhao, D. Hierarchically Ordered Macro/Mesoporous Silica Monolith: Tuning Macropore Entrance Size for Size-Selective Adsorption of Proteins. Chem. Mater. 2011, 23, 2176-2184.

(24) Dorozhkin, S. V. Self-Setting Calcium Orthophosphate Formulations: Cements, Concretes, Pastes and Putties. Int. J. Mater. Chem. 2012, 1, 1-48.

(25) Aza, P. De; Guitian, F.; Santos, C. Vibrational Properties of Calcium Phosphate Compounds. 2. Comparison between Hydroxyapatite and B-Tricalcium Phosphate. Chem. Mater. 1997, 4756, 916-922.

(26) Kazanci, M.; Fratzl, P.; Klaushofer, K.; Paschalis, E. P. Complementary Information on in Vitro Conversion of Amorphous (precursor) Calcium Phosphate to Hydroxyapatite from Raman Microspectroscopy and Wide-Angle X-Ray Scattering. Calcif. Tissue Int. 2006, 79, 354-359.

(27) Xu, J.; Butler, I.; Gilson, D. FT-Raman and High-Pressure Infrared Spectroscopic Studies of Dicalcium Phosphate Dihydrate $\left(\mathrm{CaHPO}_{4} \cdot 2 \mathrm{H}_{2} \mathrm{O}\right)$ and Anhydrous Dicalcium Phosphate $\left(\mathrm{CaHPO}_{4}\right)$. Spectrochim. Acta. A. Mol. Biomol. Spectrosc. 1999, 55, 2801-2809. 
(28) Jillavenkatesa, A.; Sr., R. A. C. The Infrared and Raman Spectra of B-and A-Tricalcium Phosphate $\left(\mathrm{Ca}_{3}\left(\mathrm{PO}_{4}\right)_{2}\right)$. Spectrosc. Lett. An Int. J. Rapid Commun. 1998, 31, 1619-1634.

(29) Puvvada, N.; Panigrahi, P. K.; Pathak, A. Room Temperature Synthesis of Highly Hemocompatible Hydroxyapatite, Study of Their Physical Properties and Spectroscopic Correlation of Particle Size. Nanoscale 2010, 2, 2631-2638.

(30) Tas, A. C. Monetite $\left(\mathrm{CaHPO}_{4}\right)$ Synthesis in Ethanol at Room Temperature. J. Am. Ceram. Soc. 2009, 92, 2907-2912.

(31) Dahlsten, P.; Kosmulski, M.; Rosenholm, J. B. Surface-Induced Electrolytic Dissociation of Oxalic and Phosphoric Acid in Mixed Alcohol-Water Solvents. Colloids Surfaces A Physicochem. Eng. Asp. 2011, 376, 42-46.

(32) Torres, L. G. Ca-Alginate Spheres Behavior in Presence of Some Solvents and WaterSolvent Mixtures. Adv. Biosci. Biotechnol. 2011, 02, 8-12.

(33) Veggi, P. C.; Martinez, J.; Meireles, M. A. A. Fundamentals of Microwave Extraction. In Microwave-assisted Extraction for Bioactive Compounds: Theory and Practice; Chemat, F.; Cravotto, G., Eds.; Springer US: Boston, MA, 2012; pp. 15-52.

(34) Perry, D. L. Inorganic Compound Data. In Handbook of Inorganic Compounds; CRC Press, Taylor \& Francis Group: Boca Raton, 2011; pp. 84-85.

(35) Kosmulski, M. Simple Model of Surface-Induced Electrolytic Dissociation of Weak Acids in Organic Solvents. Adsorption 2010, 16, 343-349.

(36) Rodrigues, A.; Lebugle, A. Influence of Ethanol in the Precipitation Medium on the Composition, Structure and Reactivity of Tricalcium Phosphate. Colloids Surfaces A Physicochem. Eng. Asp. 1998, 145, 191-204.

(37) V. Dorozhkin, S. Amorphous Calcium Orthophosphates: Nature, Chemistry and Biomedical Applications. Int. J. Mater. Chem. 2012, 2, 19-46.

(38) Keraliya, R. A.; Soni, T. G.; Thakkar, V. T.; Gandhi, T. R. Effect of Solvent on Crystal Habit and Dissolution Behavior of Tolbutamide by Initial Solvent Screening. Dissolution Technol 2010, 1, 16-21.

(39) Yin, J.; Gao, F.; Wei, C.; Lu, Q. Water Amount Dependence on Morphologies and Properties of ZnO Nanostructures in Double-Solvent System. Sci. Rep. 2014, 4, 3736.

(40) Zeng, H.; Chittur, K. K.; Lacefield, W. R. Analysis of Bovine Serum Albumin Adsorption on Calcium Phosphate and Titanium Surfaces. Biomaterials 1999, 20, 377-384. 
(41) Lee, W.; Loo, C.; Van, K. L.; Zavgorodniy, A. V; Rohanizadeh, R. Modulating Protein Adsorption onto Hydroxyapatite Particles Using Different Amino Acid Treatments. J. R. Soc. Interface 2012, 918-927.

(42) Shirahama, H.; Suzawa, T. Adsorption of Bovine Serum Albumin onto Styrene/acrylic Acid Copolymer Latex. Colloid Polym. Sci. 1985, 263, 141-146.

(43) Gao, Y.; Chen, Y.; Ji, X.; He, X.; Yin, Q.; Zhang, Z.; Shi, J.; Li, Y. Controlled Intracellular Release of Doxorubicin in Multidrug-Resistant Cancer Cells by Tuning the Shell-Pore Sizes of Mesoporous Silica Nanoparticles. ACS Nano 2011, 5, 9788-9798.

(44) Liu, T.-Y.; Chen, S.-Y.; Liu, D.-M.; Liou, S.-C. On the Study of BSA-Loaded CalciumDeficient Hydroxyapatite Nano-Carriers for Controlled Drug Delivery. J. Control. Release 2005, 107, 112-121. 